\title{
A imprensa, o Twitter e as eleições de 2010 no Brasil
}

\author{
Eduardo Nunomura*
}

\begin{abstract}
Resumo
Este trabalho examina o noticiário político e o Twitter. A investigação discute se o Twitter refletiu o agendamento proposto pelos meios de Comunicação de Massa ou se seus usuários procuraram se manifestar de forma distinta sem se submeter ao discurso da imprensa tradicional durante o segundo turno das eleições presidenciais no Brasil em 2010. Ao analisar a frequência com que a campanha eleitoral atingiu o status de trending topics, constatou-se que de cada dez tópicos populares, três eram ligados ao pleito, com mais da metade das manifestações favoráveis à candidata Dilma Rousseff. Ao confrontar esses dados com o noticiário publicado em dois veículos de circulação nacional, descobriu-se que houve discrepâncias entre o discurso da mídia e o tipo de abordagem dos assuntos que acabavam por se tornar populares na rede social.
\end{abstract}

Palavras chave: Política. Eleições. Twitter. Agenda setting. Mídia.

\section{Media, Twitter and 2010 elections in Brazil}

\section{Abstract}

This paper examines the political news and Twitter. The research discusses if Twitter reflected the agenda proposed by the Mass Media or if your users had looked for to disclose themselves of distinct form without submitting to the speech of the traditional media during the second round of presidential elections in Brazil in 2010. When analyzing the frequency in which the campaign has reached the status of trending topics, it was found that three for every ten popular

* Jornalista, foi repórter especial do jornal O Estado de S.Paulo, repórter e editor da revista Veja, e redator do jornal Folha de S.Paulo. Mestre em Ciências da Comunicação pela Universidade de São Paulo (USP), São Paulo-SP, Brasil. Bacharel em Jornalismo pela Escola de Comunicações e Artes (ECA) e em Ciência da Computação pelo Instituto de Matemática e Estatística (IME), ambas da Universidade de São Paulo.E-mail: nunomura@gmail.com 
topics were related to the election, with more than half of the demonstrations in favor of candidate Dilma Rousseff. Then, comparing these data with the news published in two major vehicles, we discovered that there was a decoupling of media's agenda and the issues that becoming popular in the social network.

Keywords: Politics. Elections. Twitter. Agenda setting. Media.

\section{Los medios de comunicación, Twitter y las elecciones de 2010 en Brasil}

\section{Resumen}

Este documento examina las noticias políticas y Twitter. La investigación analiza si el Twitter refleja la agenda propuesta por los Medios de Comunicación o si los usuarios se manifiestarán de manera diferente sin someterse a los discursos de los grandes medios en la segunda vuelta de las elecciones presidenciales en Brasil en 2010. Analizando la frecuencia con que la campaña ha alcanzado el status de trending topics, se encontró que por cada diez temas populares, tres estaban relacionados con las elecciones, y más de la mitad de las manifestaciones en favor de Dillma Rousseff. Al comparar estos datos con las noticias publicadas en dos vehículos de circulación nacional, descubrió que había una desvinculación del discurso de los medios y el enfoque de los temas que terminarán por convertirse populares en la red social.

Palabras clave: La política. Las elleciones. Twitter. Agenda setting. Los medios de Comunicación.

\section{Introdução}

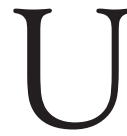

ma série de estudos recentes mostra a relevância do Twitter como uma ferramenta paradigmática de Comunicação na era das redes sociais (KEIM, CLARK, 2009; ASUR et al, 2010; CHA et al, 2010; DELLER, 2011; HERMIDA, 2010; LERMAN, GOSH, 2010; MURTHY, 2011; ROSSINI, LEAL, 2011; STEFFEN, 2011; ROMERO, MEEDER, KLEINBERG, 2011). As principais abordagens tratam do seu uso pelos cidadãos em movimentos políticos contra governos tirânicos, das possibilidades de aprimorar a conversação e o engajamento cívicos, e dos enquadramentos necessários para interpretá-lo como uma mídia diferenciada dentro do cenário da Web 2.0. Parte deles se detém em analisar, qualitativa e quantitativamente, o que as pessoas estão 
escrevendo nessa rede e encontrar explicações de por que e como determinados assuntos se tornam mais relevantes do que outros em determinados momentos. Os chamados trending topics acabam aglutinando discursos múltiplos em torno de uma mesma temática e identificam tendências do comportamento social. Investigações empíricas sobre esse assunto têm suscitado questionamentos sobre consagradas teorias das Comunicações de massa, colocando-as sob uma nova perspectiva ou revelando que seus aportes conceituais não se mostram adequados o suficiente para explicar formas modernas e contemporâneas de se comunicar.

Este trabalho examina o noticiário político e o Twitter. $\mathrm{O}$ segundo turno das eleições presidenciais no Brasil em 2010 é usado como estudo de caso. A investigação discute se o Twitter refletiu o agendamento proposto pelos meios de Comunicação de Massa ou se seus usuários procuraram se manifestar de forma distinta sem se submeter ao discurso da imprensa tradicional. Teria essa rede social proporcionado aos eleitores novos meios de se comunicar sobre a política? Nesta investigação, focamos a análise sobre os trending topics do Brasil (TTBr), que servirão de indicador dos temas mais populares de campanha. Ao mesmo tempo, confrontaremos esses dados com as principais notícias políticas publicadas pelo jornal Folha de S.Paulo e pela revista Veja - os dois impressos de maior circulação nacional -, procurando aferir a hipótese de Agenda setting no contexto das redes sociais.

ASUR et al (2010, p.7) afirmam que para um determinado assunto permanecer em discussão por bastante tempo dentro do Twitter é vital que muitas pessoas estejam alimentando continuamente esse tema. Uma miríade de assuntos é postada pelos cidadãos a todo instante, mas apenas um conjunto reduzido deles acaba por ganhar o status de trending topic. É um indicativo de que os tópicos populares são, assim, um instrumento capaz de resumir as principais temáticas que estão em debate na sociedade. $O$ presente estudo optou por testar a validade do uso dos TTBrs para medir a saliência temática, mas reconhece a existência de softwares de monitoramento que buscam aferir com maior precisão o registro das conversações. Trata-se, aliás, de uma sugestão para investigações futuras. 
Primeiro analisamos a frequência com que a campanha eleitoral atingiu o status de TTBr, constatando que de cada dez tópicos populares, três eram ligados às eleições no período entre 4 a 31 de outubro de 2010. Depois, detemos nossa investigação apenas sobre aqueles que diziam respeito à política, descobrindo que houve um predomínio de manifestações favoráveis à candidata Dilma Rousseff, acima dos posicionamentos neutros e daqueles em favor do candidato José Serra. Para contrapor com a agenda da mídia, foram selecionadas todas as reportagens de política que diziam respeito à campanha no mesmo período, excetuando-se as colunas opinativas e de notas políticas.

Uma das constatações de relevo deste trabalho é detectar um descolamento entre o discurso da mídia e a abordagem dos assuntos que acabavam por se transformar em trending topics. Em muitas ocorrências, os próprios veículos de Comunicação se tornaram tópicos populares, porém com sinal trocado. Isto é, o mote principal dos eleitores era contestar e criticar pelo Twitter a cobertura midiática que vinha sendo feita da campanha. Estudos anteriores sobre temas não-políticos indicam justamente o contrário: as redes sociais tendem a funcionar como um grande amplificador do conteúdo gerado pelas mídias tradicionais.

\section{Um pouco sobre o Twitter}

O Twitter é um popular microblog que permite aos usuários enviar e ler textos de até 140 caracteres (uma média de 11 palavras por mensagem), mais conhecidos como tuites ("tweets"). $\mathrm{O}$ site foi criado em março de 2006 por Jack Dorsey e seu lançamento foi em julho daquele ano. Em pouquíssimo tempo, tornou-se uma das redes sociais mais famosas do mundo, contando em 2011 com 100 milhões de usuários ativos e disponível em 17 idiomas diferentes. Cerca de 40 milhões deles usam o site para se informar ${ }^{1}$. A análise de seu conteúdo, tecnicamente fácil de ser obtido, tem sido alvo de interesse de acadêmicos e empresas que querem

\footnotetext{
${ }^{1}$ Informações coletadas do blog oficial do Twitter. Disponível em: http://blog. pt.twitter.com/2011/09/cem-milhoes-de-vozes.html. Acesso em: 5 dez 2011.
} 
estudar o que as pessoas estão falando sobre um determinado assunto. $\mathrm{O}$ conjunto das comunicações existentes nas redes sociais oferece uma nova forma de se investigar e compreender os relacionamentos, chegando a ser reconhecido como uma pesquisa de opinião instantânea. DELLER (2011) defende que o Twitter nos fornece não só um termômetro da opinião pública, como permite aperfeiçoar a própria compreensão sobre a audiência, que mescla desde a impressão pessoal dos usuários até a influência, dentro de uma "Twittesfera" (o universo das comunicações que ocorrem dentro do Twitter), da informação circulante entre celebridades, jornalistas e organizações. "O serviço oferece um interessante exemplo de convergência entre a 'velha' e a 'nova' mídia e entre 'produtores' e 'consumidores'”, indica JENKINS (2006a, apud DELLER, 2011, p.216).

É dentro dessa esfera particular que se insere o Twitter. Cada um de seus usuários pode escrever tuites livremente, respondendo à questão "O que está acontecendo?". Opcionalmente, pode incorporar à mensagem uma hashtag (\#Twitter, por exemplo), indicando que seu micropost é parte de uma discussão mais ampla dentro de um tópico. As comunicações feitas nesse ambiente podem ou não ter sequência, sendo repetidas por outras pessoas (retuites) como parte de um ou muitos discursos que acontecem a cada instante no site. A página inicial do Twitter mostra uma lista dos dez trending topics do momento, sendo possível configurar, desde janeiro de 2010, sobre quais localidades se quer obter essa informação. No país, existem 16 configurações possíveis: Brasil e as cidades de Belo Horizonte, Belém, Brasília, Campinas, Curitiba, Fortaleza, Goiânia, Guarulhos, Manaus, Porto Alegre, Recife, Rio de Janeiro, Salvador, São Luís e São Paulo.

Uma palavra ou uma expressão atinge o status de trending topics quando os motores de busca do Twitter "entendem" que esse tema se tornou recorrente e popular entre as discussões propostas pelos usuários. CHA et al (2010) analisaram episódios marcantes, e plenamente midiáticos, do ano de 2009, e constataram que a morte de Michael Jackson envolveu mais de 600 mil usuários em um mês, gerou 1,4 milhão de tuites e rendeu uma audiência de 
23,6 milhões de pessoas ${ }^{2}$. Os trending topics \#iranelection e names of politicians, relacionados à convulsão social no Irã entre 11 de junho e 10 de agosto daquele ano, foram utilizados por $300 \mathrm{mil}$ usuários, que geraram 1,5 milhão de tuites lidos por 22,2 milhões de pessoas no mundo todo. Este trabalho concentrará a análise sobre os TTBrs do segundo turno da última eleição presidencial. Segundo o site What The Trend ${ }^{3}$, um dos muitos serviços criados para monitorar o Twitter, os tópicos sobre a política brasileira foram muito intensos e, reunidos como um único assunto, alcançaram o $26^{\circ}$ posto mundial em 2010 - à frente das discussões sobre o Google, o Twitter e o resgate de mineiros chilenos, porém, atrás do cantor Justin Bieber, da Copa do Mundo e da fabricante de eletroeletrônicos Apple.

Vamos proceder a investigação empírica do material discursivo da mídia com base na análise de conteúdo proposto por BARDIN (1977). Por meio dessa técnica, foram criadas categorias que permitirão enquadrar o noticiário sobre o segundo turno da campanha presidencial de 2010 no Brasil. O método:

[...] pretende tomar em consideração a totalidade de um texto, passando- o pelo crivo da classificação e do recenseamento, segundo a freqüência de presença (ou de ausência) de itens de sentido. Isso pode constituir um primeiro passo, obedecendo ao princípio de objetividade e racionalizando através de números e percentagem, uma interpretação que, sem ela, teria de

\footnotetext{
${ }^{2}$ A maioria dos internautas opta por apenas ler as mensagens (receptores), o que faz com que a audiência de um treding topic seja sempre superior ao número de emissores.

${ }^{3}$ Segundo o http://yearinreview.whatthetrend.com/, os TTBrs da política brasileira mais comentados foram Dilma, \#marina43, Tiririca, \#serrarojas, Serra comedor, \#virada45, \#voude13, Marina Silva, \#13neles, Gilmar Mendes, \#13confirma, José Alencar, Ficha Limpa, Horario Politico, Erenice, \#dia31vote13, Propaganda Eleitoral, Weslian Roriz, Baixada Santista, Zona Eleitoral, Silas Malafaia, Erenice Guerra, Mesário, Dilma Pokémon, Deputado Federal, Plínio Arruda, \#OndaVerde, \#debatefolhauol, Fatima Bernardes, Aloysio Nunes, Parabéns Dilma, \#dilmafactsbyfolha, \#lulablogs, \#orgulhodesernordestino, CPMF, \#boladepapelfacts, \#soumaisdilma, Plínio, \#br45il, Tiririca eleito, Tiririca Morreu, Debate Presidencial, Beringhs, Saneamento Básico, Urnas Apuradas, Salto triplo carpado, Seções Apuradas, Santinhos, \#euquero45. Nos casos de Baixada Santista e Salto triplo carpado, não fica claro se e por que eles tiveram, de fato, relação com a campanha eleitoral. Acesso em: 5 dez. 2011.
} 
se sujeita a aval. É o método das categorias, espécie de gavetas ou rubricas significativas que permitem a classificação dos elementos de significação constitutivas, da mensagem. É, portanto, um método taxionômico bem concebido para [...] introduzir uma ordem, segundo certos critérios, na desordem aparente (BARDIN, 1977, p.37)

Utilizaremos as mesmas categorias para enquadrar os TTBrs, embora seja preciso ressaltar que a técnica de análise de conteúdo não será feita sobre os tuites. Por se tratar de uma ferramenta que limita a mensagem a 140 caracteres, seria arriscado definir alguma classificação que fosse capaz de refletir o conteúdo e o direcionamento dos discursos presentes nesse tipo de Comunicação. Em outras palavras, se um eleitor escrevesse os tuites "Dilma Rousseff foi guerrilheira" ou "José Serra presidiu a UNE na ditadura", seria impossível declinar se ele se manifestou contra, a favor ou de forma neutra sobre os candidatos. Para solucionar esse impasse, serve como contra-argumento o estudo de ROMERO, MEEDER e KLEINBERG (2011, p.4), que descobriram que o nível de concordância entre as pessoas que usam os mesmos trending topics é elevado e uniforme. Numa análise sobre o uso de hashtags políticos para a compreensão do comportamento da audiência, os autores revelam que, mesmo no caso de temas políticos polêmicos, valeria o princípio da Sociologia do "complexo de contágio" (CENTOLA, 2007, apud ROMERO, MEEDER, KLEINBERG, 2011, p.1), segundo o qual exposições contínuas e repetidas sobre um assunto são cruciais para a propagação de ideias controversas ou que geram contenciosos.

\section{Garimpo digital}

O segundo turno das eleições de 2010 começou no dia 4 e se encerrou com a ida às urnas em 31 de outubro. Durante esses 28 dias de reta final, a política esteve no centro das atenções midiáticas, com os veículos de Comunicação dedicando amplo espaço editorial para a cobertura das campanhas da petista Dilma Rousseff e do tucano José Serra, além de outros personagens que, direta ou indiretamente, poderiam influenciar o andamento da disputa política. O jornal Folha de S.Paulo, nos dias posteriores 
ao primeiro turno e também nos anteriores ao segundo, criou um caderno especial de eleições. As capas de quatro edições de Veja no período versaram sobre o tema - no ano todo, de 52 capas 18 foram políticas. Com o crescimento das campanhas eleitorais, cada vez mais dependentes dos marqueteiros, é natural que a imprensa se interesse e dedique parte considerável de seu esforço nesse tipo de cobertura.

Na última disputa eleitoral, o Twitter já havia se tornado uma ferramenta de grande utilidade para os candidatos, suas equipes de campanha, profissionais de mídia e a população. Era possível acompanhar as agendas dos candidatos e as repercussões simultâneas e posteriores de debates televisivos. Segundo STEFFEN (2011), que analisou os tuites dos presidenciáveis, Serra foi o mais eficiente no uso do site, dando mostras de que ele escrevia seus microposts, enquanto não se podia dizer o mesmo de Dilma. Tal estudo, contudo, serve apenas de indicativo sobre a forma como o Twitter foi incorporado na rotina da campanha pelos políticos (emissores), não explorando o conteúdo dos discursos, nem se e como repercutiam perante o eleitorado (receptores).

O corpus da pesquisa utilizado foi a base de dados disponível no site TTBr.info, cuja proposta é, por meio de uma rede colaborativa de usuários do Twitter, construir os significados dos TTBrs. A explicação dos tópicos populares pode ser feita por qualquer um, segundo informa o site. A listagem é produzida a partir de um sistema de pontuação que varia conforme a posição e o tempo do termo na lista dos dez assuntos mais comentados no Twitter. Embora esse ranking informe diariamente os 20 TTBrs mais frequentes e influentes, optamos pela extração dos dez primeiros tópicos para cada dia do segundo turno da campanha. Dessa forma, para os 28 dias analisados, foram coletados 280 TTBrs. Extraídos apenas os que tinham conotação política, chegou-se a um total de 93 (33\% do total dos dados) $)^{4}$.

${ }^{4}$ Como alguns dos TTBrs se repetiram ao longo dos dias, foram contabilizados 53 tópicos únicos (do conjunto de 93 tópicos políticos). 


\section{Dados e métodos}

\section{A. Categorização e enquadramento}

Foram estabelecidas três categorias para a análise do material discursivo que tinha como origem os TTBrs: Pró-Dilma, Pró-Serra e Neutro. Pela característica do Twitter, é preciso ressalvar que um tópico pode ser usado livremente por qualquer usuário no sentido e na conotação que melhor julgar. Assim, nada o impedirá de expressar sua opinião contrária ao sentimento que originou um TTBr e mesmo à da maioria das pessoas que estão se manifestando. Um exemplo: embora a hashtag \#dilmanão tenha surgido logo no início do segundo turno a partir de um tuite de um militante ou simpatizante do bloco oposicionista, um partidário da base aliada poderia se manifestar livremente usando o mesmo tópico na tentativa de responder aos ataques ou contrapor seus pontos de vista. Esse é o espírito democrático da rede social.

Apesar disso, cabe esclarecer que, na prática, as manifestações que são identificáveis de um lado são ignoradas ou rebatidas de outras formas pelo campo adversário, inclusive criando outros tópicos favoráveis ao seu candidato. Para um \#dilmanão contrapõe-se um \#aiatolaserra, por exemplo. Surge, dessa forma, uma vívida disputa pelos primeiros lugares nos TTBrs, uma espécie de prêmio a ser conquistado. Quem gosta de azul fala com quem gosta de azul e quem gosta de vermelho se dirige só a quem gosta de vermelho. Para a categorização se tornar possível, optou-se por sinalizar como Neutro qualquer TTBr que não fosse facilmente identificado com um dos lados da disputa política. Exemplificam essa categoria: Politicamente Incorreto, Debate Presidencial, CNT/ Sensus, \#debatenarecord, Alexandre Garcia, entre outros.

Em relação aos tópicos favoráveis a um ou ao outro candidato, a categorização foi feita com base na realidade política-histórica do Brasil e pelo andamento da campanha. Um tópico como serramilcaras, que chegou ao topo dos trending topics no dia $11 \mathrm{de}$ outubro, foi considerado Pró-Dilma por ter surgido a partir de uma peça de campanha petista para o Horário do Programa Eleitoral Gratuito (HPEG), no qual o tucano era considerado como um 
político que escondia seu passado político. O tópico \#ptmente, que se tornou o segundo mais comentado em 23 de outubro, surgiu por ação de eleitores de Serra que contestavam supostas mentiras no programa de Dilma e acabaram por render direitos de resposta ao candidato tucano. Com base nesses critérios, chegou-se à seguinte distribuição para os 93 tópicos políticos:

\begin{tabular}{lll}
\hline Categoria & TTBr & $\%$ \\
Pró-Dilma & 51 & $55 \%$ \\
Pró-Serra & 19 & $20 \%$ \\
Neutros & 23 & $25 \%$ \\
\hline
\end{tabular}

A militância petista teve muito mais ânimo e disposição para fazer valer suas posições. Durante 18 dias, os temas Pró-Dilma permaneceram por mais tempo em primeiro lugar e em oito dias, no segundo posto. Já os partidários do tucano conseguiram que apenas 1 TTBr Pró-Serra atingisse o topo dos tópicos populares, em 9 de outubro, e em seis dias ficaram em segundo lugar (mas, nessas datas, os simpatizantes da petista ocuparam o topo dos TTBrs, "vencendo" essa disputa simbólica). O gráfico abaixo com a distribuição dos tópicos dá medida da predominância dos tuites Pró-Dilma em relação aos Pró-Serra e Neutros:

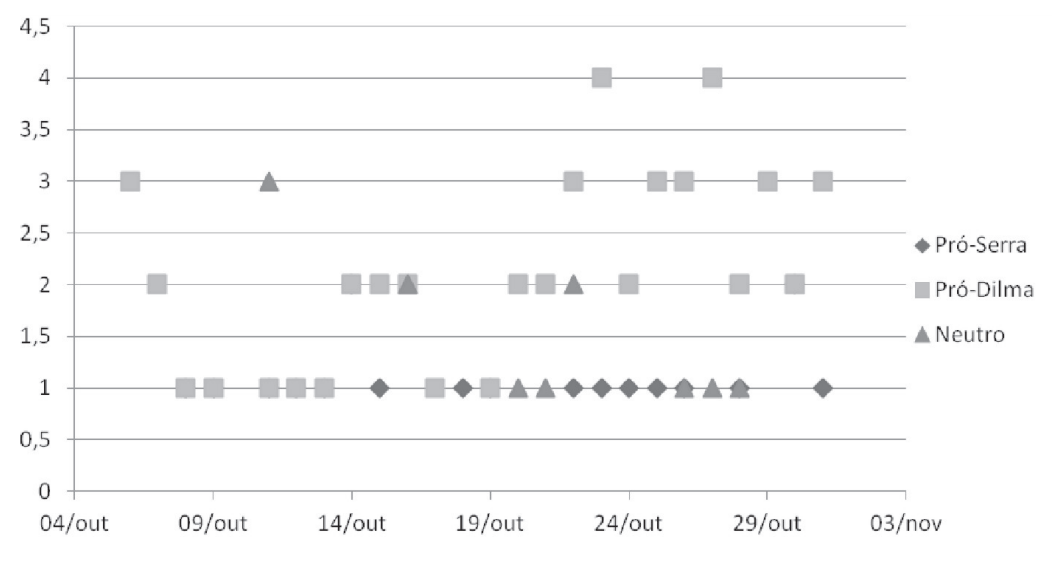




\section{B. Agenda setting}

Dentro das pesquisas comunicacionais, os estudos dos efeitos de longo prazo se mostram mais eficazes em elucidar o papel dos Meios de Comunicação do que o paradigma dos "efeitos limitados", conforme afirma WOLF (2008, p.140). Citando LANG-LANG (1962), o autor lembra que em situações como as campanhas eleitorais muitas vezes se deixa de lado analisar o impacto da mídia, o cumulativo, e se torna mais desencorajadora investigações sobre a visibilidade de outros tipos de influências que não aquelas produzidas pela mídia de massa. E é exatamente por essa razão que é fundamental recorrer a outras medidas capazes de medir os efeitos a respeito do conteúdo e do significado daquilo a que se expõe.

A hipótese da agenda-setting desenvolve-se partindo de um interesse geral para o modo como as pessoas organizam e estruturam a realidade circunstante. A metáfora da agenda-setting é uma macrodescrição desse processo [...]. Ela se baseia em algumas admissões e interrogações específicas sobre o tipo de estratégias ativadas pelos indivíduos quando estes estruturam o próprio mundo. Por exemplo, a típica medida da agenda da mídia - que articula temas conforme a freqüência das suas referências - baseia-se no pressuposto de que a freqüência com que um tema ou argumento aparece é uma indicação relevante usada pelos destinatários para avaliar sua saliência (MCCOMBS, 1981, p. 211, apud WOLF, 2008, p.167).

Nesta investigação, a agenda da mídia será dada pela análise de conteúdo do conjunto discursivo de reportagens produzidas pelo jornal Folha de S.Paulo e pela revista Veja, também no segundo turno da campanha eleitoral. Já a agenda do público corresponderá à análise preliminar feita neste estudo sobre os TTBrs políticos. Esse procedimento é válido, tomando como referência DELLER (2011, op.cit.). Já para ASUR et al (2010, p.1), que chegaram à conclusão de que poucos tópicos tendem a durar por muito tempo ao longo de um dia, enquanto a maioria permanece entre os dez mais populares entre 20 e 40 minutos, são as questões mais persistentes, originadas pela mídia ou por alguns poucos usuários, que irão capturar a grande audiência e contribuir para a formação da agenda do público. MURTHY (2011) questiona qual forma de interação o Twitter tem provocado e se os cidadãos estariam produzindo e con- 
sumindo notícias de outras pessoas comuns. "Notícias produzidas por usuários do Twitter experimentam uma fama de curta duração só até o público começar a seguir histórias de interesse produzidas pelos profissionais de mídia" (MURTHY, 2011, p.779).

Embora teóricos como WOLF (2008, p.174) alertem para a dificuldade de se definir o frame temporal para mensurar os efeitos de uma agenda sobre a outra, e que a simples escolha já incorra numa influência sobre os resultados da pesquisa, no caso de uma campanha eleitoral nos dias atuais há que se levantar em conta a redução do chamado time-lag. A dinâmica de uma eleição se dá quase imediatamente, e na era das redes sociais, é mais do que esperado que um programa partidário ou um debate político transmitidos pela TV repercutam imediatamente no Twitter. Para os veículos impressos, o efeito do noticiário midiático deve variar de um dia a, no máximo, uma semana. Efeitos posteriores podem ter ocorrido, mas fogem ao escopo deste trabalho.

No cruzamento das agendas do Twitter e da imprensa, alguns dados merecem ser destacados de partida. Das 149 reportagens que a Folha publicou sobre a campanha presidencial, 29 (19\% do total) tiveram alguma relação direta ou indireta com os TTBrs. No caso de Veja, de 19 textos, quatro (21\%) podiam ser associados a algum trending topic. Embora fosse razoável supor que nem tudo o que um veículo de Comunicação impresso publica ganhe repercussão, percebe-se pelos porcentuais acima que a influência desse discurso midiático foi longe de ser considerada expressiva.

A revista publicou no domingo eleitoral, em 3 de outubro, uma capa sobre o que esperar dos presidenciáveis, mas seria pouco provável acreditar que alguma de suas reportagens (frias, no jargão jornalístico) poderia ter alguma repercussão nos dias seguintes. Já o noticiário do jornal, com os resultados eleitorais, destacava como uma das causas para explicar o 2 o turno a arrancada da candidata Marina Silva (PV), e esse fato acabou indo parar nos TTBrs. Dois dias depois, a Folha publica reportagens sobre mudanças de estratégia de Dilma e a entrada de Ciro Gomes em auxílio à campanha da petista no Nordeste, assuntos que também ganharam destaque no Twitter. 
Em 11 de outubro, a Folha publica reportagens sobre o debate da TV Bandeirantes, na qual houve troca de acusações entre Dilma e Serra. Esses textos do jornal, somados aos de outros veículos, poderiam, por hipótese, ensejar uma repercussão no serviço online, o que foi registrado com três TTBrs correlacionados a esse assunto. Nos dias seguintes, Folha e Veja incluem em sua agenda a temática do aborto, dando voz ao candidato tucano, à Conferência Nacional dos Bispos do Brasil e a um discurso defensivo de Dilma. Esses temas também tiveram saliência no Twitter.

A capa da revista de 13 de outubro dava o tom dessa cobertura midiática: nela, a petista aparecia duas vezes, uma imagem em oposição à outra e com frases contraditórias sobre o que ela já havia dito sobre o tema do aborto. Na semana seguinte, Veja publica uma capa sobre o mineiro Aécio Neves (PSDB) e uma reportagem sobre Erenice Guerra, então ministra da Casa Civil, acusada pela imprensa de nepotismo e corrupção. A Folha também passou a publicar textos acusatórios contra a auxiliar de Dilma, mas esses temas não tiveram repercussão de longa duração no Twitter.

O caso Erenice, que foi alvo de denúncias apresentadas pela Folha e Veja, e depois acompanhadas por demais veículos, rendeu 16 reportagens no jornal e quatro na revista, o que denota ter havido um investimento da imprensa nessa cobertura específica. Mas apesar desse esforço jornalístico o eleitor de Serra só foi capaz de traduzir o caso midiático em um único TTBr, Amaury Ribeiro (jornalista que teria sido contratado pela equipe de Dilma para criar dossiês contra Serra). Pode-se aventar a hipótese de que a militância de Dilma conseguiu neutralizá-lo, o que é menos provável já que nessa rede social dificilmente se controla tendências e opiniões contrárias.

Diferente da repercussão de uma reportagem da revista IstoÉ sobre Paulo Preto, o ex-diretor da Dersa Paulo Vieira de Souza, acusado pelo PT de ser um operador de caixa 2 tucano e de quem se dizia que havia fugido com $\mathrm{R} \$ 4$ milhões da campanha de Serra. A capa fazia uma proposital montagem com Serra semelhante à que fez Veja com Dilma duas semanas antes. A hashtag \#paulopreto virou trending topic, a partir do destaque dado por simpatizantes 
do PT que criticavam a imprensa por não publicar notícias sobre esse personagem. A Folha se rendeu ao assunto e acabou publicando sete reportagens com o personagem até o fim das eleições. Veja ignorou o tema. Vale frisar que esse episódio só veio à tona a partir de uma acusação da candidata Dilma feita num debate televisivo no dia 10 de outubro.

No restante da cobertura, o que se nota é um aumento do distanciamento entre as agendas da mídia e do Twitter. $\mathrm{O}$ que se verifica é um crescente descontentamento dos usuários do site em relação ao noticiário publicado pelos veículos de Comunicação, o que será detalhado na seção seguinte.

\section{A mídia nos TTBrs}

Muitos TTBrs surgiram por força e vontade própria dos eleitores, independente da agenda da mídia. Não seria esperado localizar reportagens que tivessem ligação direta com tópicos populares como \#brasil13, \#dia31 vote13, \#mulhervota13, Buarque (o cantor Chico que declarou seu apoio à Dilma), \#sejamais1 dilma, \#soumaisdilma, \#dilmaday, \#voude13, todos Pró-Dilma, e \#vaidarvirada, \#virada45 e \# euquero45, estes Pró-Serra. Eles expressaram a força da militância virtual, e também das equipes de campanha que conseguiram mobilizar os eleitores de cada lado da disputa em torno de seus candidatos. O fato de ter havido mais TTBrs em favor de Dilma pode indicar que a estratégia de campanha na internet da presidenciável foi mais eficaz ou, ainda como um hipótese a ser demonstrada, que essa tendência traduziu o sentimento do eleitorado, uma espécie de termômetro da opinião pública. $O$ resultado das urnas e das pesquisas de opinião, como as da Datafolha ${ }^{5}$ que sempre indicaram vantagem de Dilma sobre Serra, apontam para essa última direção.

Nesta seção, um ponto de destaque é a repercussão no Twitter, e a forma como esta se deu, sobre a cobertura da mídia na cam-

\footnotetext{
${ }^{5} \mathrm{O}$ instituto de pesquisas ligado ao jornal Folha de S.Paulo realizou cinco sondagens no segundo turno, e a oscilação de Dilma sempre foi de um ponto para mais ou para menos sobre os 55 pontos porcentuais - a diferença ficava para Serra na contagem dos votos válidos.
} 
panha. Um dos temas que incendiaram a campanha no início do segundo turno foi o aborto, a partir de uma mudança no discurso político da candidata Dilma. Em 2007, ela se posicionava a favor da descriminalização e às vésperas do primeiro turno se declarou contra. A mídia explorou essa questão em seus espaços mais nobres - como em manchete principal da Folha ${ }^{6}$ e capa da Veja ${ }^{7}$. Algumas das ocorrências do tópico \#dilmanão podem ser atribuídos a esse debate. Mas foi a partir do dia 16 de outubro, com uma entrevista à Folha ${ }^{8}$ de uma ex-aluna afirmando que Mônica Serra, mulher do candidato, também havia feito aborto, que se percebe uma mudança no comportamento dos eleitores.

A colunista Mônica Bergamo, da Folha, foi alvo de ataques ferozes de eleitores de Serra. No dia seguinte à publicação da entrevista da ex-aluna, a jornalista virou um tópico popular com \#monicabergamosuja. É um caso de agendamento, ainda que de sinal trocado. Pela hipótese desse clássico estudo, "a asserção fundamental da Agenda setting é que a compreensão das pessoas em relação a grande parte da realidade social é modificada pelos Meios de Comunicação de Massa" (SHAW, 1979, pp.96, 101, apud WOLF, 2008, p.143). Ao revelar a contradição do candidato Serra, que condenou publicamente a mudança de posicionamento de Dilma, mas ao mesmo tempo ocultava que sua mulher já havia feito o aborto, a profissional acabou sendo duramente criticada.

Em outras situações, a cobertura da mídia foi intensamente debatida na agenda do público, o que pode ser traduzido pelo surgimento de outros 6 TTBrs. Por meio dos tópicos \#boladepapelfacts, \#serrarojas, \#globomente, \#vejamente, Maria Rita Kehl e Kamel, os eleitores fizeram questão de demonstrar sua insatisfação contra algumas reportagens. A Folha publicou que "Serra é agredido

6 Folha de S.Paulo, de 5 out 2010.

${ }^{7}$ Revista Veja, de 13 out 2010.

${ }^{8}$ Esse caso envolveu outra rede social, o Facebook. Foi a partir de um desabafo dessa ex-aluna em seu perfil pessoal que o jornal Brasil de Fato, de viés de esquerda e baixa circulação, publicou o assunto. Mas a história só ganhou visibilidade midiática quando a Folha decide publicá-la. 
durante confronto no Rio" ${ }^{\text {, }}$ reportando o fato no dia seguinte ao acontecido. Mas um vídeo do SBT que circulou nessa data indicava que apenas um pedaço de papel amassado havia atingido o candidato. Foi o bastante para que os eleitores de Dilma criassem TTBrs irônicos ao episódio, mas também contestando o noticiário que assumia como verdadeira a versão dos fatos apresentada pela campanha tucana. Naquela noite, a Rede Globo abriu o programa Jornal Nacional com uma reportagem de 7 minutos, afirmando que Serra teria sido atingido por um segundo objeto - chegou a levar um perito criminal para analisar vídeos e imagens fotográficas. A hashtag \#globomente, primeiro lugar no dia 23 de outubro, surgiu como um protesto instantâneo de simpatizantes de Dilma contra essa reportagem da Rede Globo. A Folha também comprou essa versão: "Dois objetos foram atirados contra Serra durante confronto no Rio"10. A versão online da revista Carta Capital ${ }^{11}$ chegou a produzir uma coletânea de tuites, ressaltando que, naquele momento, os TTBrs \#boladepapelfacts e \#serrarojas (uma alusão ao goleiro chileno Roberto Rojas, que simulou ter sido atingido por um objeto numa partida contra o Brasil) ocupavam não só os trending topics brasileiro como mundial:

@ realaugusto: folhas A4 apenas com porte de arma, A3 será restrito às Forças Armadas \#boladepapelfacts \#serrarojas

@Esquilo_: \#SerraRojas promete aviõezinhos de papel vigiando todas as fronteiras!

@opetista: Bolinha de papel: $\mathrm{R} \$ 0,50$, Consulta: $\mathrm{R} \$ 150$, Tomografia: $\mathrm{R} \$ 600$, Ver o \#SerraRojas fingindo: Não tem preço. \#BoladePapelFacts

@neisimasx: detectores de metal serão substituídos por detectores de papel em todos os aeroportos do mundo \#serrarojas

@outramidia: Ministério da Saúde adverte: bolinha de papel causa tontura e náuseas em políticos mentirosos \#serrarojas \#boladepapelfacts

@Pedro_Ranieri: Polícia encontra um arsenal de armas na casa do agressor de \#SerraRojas contendo cartolina, papel almaço, crepom, e 100 folhas de fichário

\footnotetext{
${ }^{9}$ Folha de S.Paulo, de 21 out 2010, p.A8.

${ }^{10}$ Folha de S.Paulo, de 22 out 2010, p.A12.

${ }^{11}$ Revista Carta Capital. Disponível em http://www.cartacapital.com.br/politica/o-melhor-da-boladepapelfacts/. Acesso em: 5 dez 2011.
} 
Na última edição antes da votação do segundo turno, Veja publicou o texto "Pau na democracia" sobre o episódio da bolinha de papel, em que a revista considera que um segundo objeto atingiu o candidato Serra, mas o pior teria sido a reação de militantes petistas, de Dilma e do presidente Lula:

Trata-se de algo absolutamente inaceitável numa sociedade democrática.

Também é espantoso como a candidata petista Dilma Rousseff e o presidente da República reagiram ao ocorrido. Eles não só negaram a agressão sofrida por Serra, como ainda tentaram criminalizar a vítima (Veja, p.76-77).

Este texto não chegou a virar alvo de protestos no Twitter. Porém, a reportagem de capa, "A verdade sobre dossiês"12, que trazia a denúncia de que Dilma e Gilberto Carvalho cobravam do ex-secretário-nacional de Justiça Pedro Abramovay, a produção de dossiês de campanhas, não foi poupada. A publicação chegou às bancas no sábado 23 de outubro, e por três dias seguidos provocou a ira de eleitores da petista expressos no trending topic \#vejamente. Por outro lado, simpatizantes de Serra conseguiram fazer com que o TTBr Gilberto Carvalho ficasse entre os mais populares, um exemplo claro do agendamento produzido pela mídia nesse episódio.

Um outro exemplo que deixa claro o descolamento entre a agenda da mídia e a agenda do público é o tópico Maria Rita Kehl, que nos dias 6 e 7 de outubro, alcançou os trending topics mundiais e brasileiros. Tratava-se do desligamento da psicanalista como colaboradora do jornal $\mathrm{O}$ Estado de S. Paulo. Na versão que tomou conta do Twitter, o motivo teria sido uma coluna que ela havia escrito elogiando o programa do governo federal Bolsa-Família. Diante da falta de explicações claras e convincentes sobre o episódio, inúmeras mensagens foram postadas criticando a postura do jornal e que o caso servia de exemplo para mostrar que a imprensa de circulação nacional, de maneira geral, estava atuando em favor da campanha de Serra.

\section{O viés da cobertura}

Para fornecer mais subsídios para a análise comparativa, procurou-se categorizar também o noticiário dos dois veículos

${ }^{12}$ Revista Veja, de 27 out 2010. 
analisados adotando-se os mesmos parâmetros aplicados sobre os trending topics, conforme descrito no item A. Ou seja, para cada notícia encontrada que dizia respeito à campanha presidencial, procurou-se categorizá-la segundo os critérios de valências Pró- Dilma, Pró-Serra ou Neutro. Por conta disso, em certos textos, teve-se de recorrer a uma classificação subjetiva sobre como se poderia enquadrar um discurso segundo as categorias acima.

Para criar um padrão analítico, considerou-se que uma reportagem que criticava a conduta da candidata Dilma deveria ser interpretada como sendo Pró-Serra. Se fosse o contrário, isto é, uma crítica ao presidenciável tucano, a notícia foi ponderada como sendo Pró-Dilma. Os textos que ressaltavam aspectos positivos de apenas um dos lados da disputa seguiram para seus respectivos candidatos. É importante acrescentar que esse enquadramento não implica em dizer, strito sensu, que o veículo foi petista ou tucano, mas identificar se a reportagem poderia favorecer um ou outro lado político. Justifica-se a adoção desse procedimento para facilitar a comparação entre os dois conjuntos de dados (os TTBrs e as reportagens da imprensa), criando mais elementos para mostrar o descolamento entre as duas agendas.

Do conjunto de textos analisados, que constituem para este trabalho a agenda da mídia, a Folha apresentou uma cobertura mais equilibrada, com $42 \%$ deles mais favoráveis ao candidato Serra, 31\% à presidenciável Dilma e $27 \%$ foram tidos como neutros. Já a revista Veja adotou uma postura crítica em relação à candidata da situação, publicando apenas um texto que pudesse ser considerado favorável a ela ("Apadrinhada, favorita e cheia de mistérios (sobre Dilma)"13). Em relação ao tucano, foram 12 textos que o apresentavam de forma positiva perante o eleitorado e seis que eram neutros.

$\mathrm{Na}$ maioria das vezes em que houve convergência entre as agendas da mídia e do público, ela ocorreu em episódios mais do que esperados, como a cobertura dos debates televisivos (que geraram os TTBrs \#debateband, Debate Presidencial, \#debatenarecord), o tema religioso que ganhou força no fim do primeiro turno

\footnotetext{
${ }^{13}$ Revista Veja, de 4 out 2010.
} 
e continuou no início do segundo (Silas Malafaia e \#dilmanão), o episódio da bolinha de papel (\#boladepapelfacts) e a divulgação das pesquisas de opinião e o caso Paulo Preto (\#paulopreto). Os fatos noticiosos se impunham por si. Não se pode, nesses episódios, garantir que foi por causa do discurso da imprensa que os eleitores começaram a apresentar seus pontos de vista no Twitter. Durante uma disputa eleitoral, cada candidato lança mão de vários artifícios para influenciar a opinião pública, inclusive pelo HPEG, que está sob controle de suas equipes de marketing.

Importante contextualizar que a disputa em 2010 ocorreu por conta do crescimento dos votos dados à candidata Marina Silva, impedindo a vitória antecipada da petista. A Folha afirmou, logo nos primeiros dias do segundo turno, que a presidenciável verde tinha conquistado o voto religioso e de classe média e, como resposta, o Partido dos Trabalhadores já se propunha a rever suas posições sobre temas delicados, como se vê claramente nos textos "PT já discute retirar aborto do programa de governo" $14 \mathrm{e}$ "Dilma debate homofobia com evangélico" ${ }^{15}$. No entanto, com a divulgação de uma pesquisa de opinião, o jornal indica que o "Caso Erenice mudou mais votos que temas religiosos" ${ }^{16}$, dando um novo norte para a cobertura da campanha. A discussão de fundo religioso permaneceu, mas as denúncias de corrupção contra a ministra da Casa Civil, ex-auxiliar direta de Dilma, passaram a dominar o espaço editorial desses dois veículos.

\section{Discussão proposta}

O segundo turno das eleições presidenciais de 2010 evidencia que: 1) o Twitter foi utilizado como instrumento de persuasão, fortalecimento de convicções e palco de debates públicos pelos eleitores, com sinais de que a campanha de Dilma conseguiu mobilizar melhor seus simpatizantes em torno da candidata; 2) a hipótese de Agenda setting deve ser vista com ressalva nesse período, porque se

${ }^{14}$ Folha de S.Paulo, de 5 out 2010, p.A1 e Especial 1.

${ }^{15}$ Folha de S.Paulo, de 7 out 2010, p.A8.

${ }^{16}$ Folha de S.Paulo, de 11 out 2010, p.A4. 
notou pouca saliência entre o discurso midiático e as manifestações expressas nas redes sociais; e 3) a mídia foi intensamente debatida e criticada por causa de sua cobertura eleitoral.

A mobilização de cidadãos nas redes sociais se tornou um tema central para as equipes das campanhas eleitorais. Com o aumento de pessoas conectadas, que buscam informações e trabalham em redes, as ferramentas digitais se mostram como uma solução rápida e direta para estreitar relacionamentos políticos com a sociedade. Ainda que a realidade social mostre que estamos falando de um país de profundas assimetrias de acesso, a tendência irreversível é de caminharmos para a solução desses impasses. Se por ora ainda falamos de redes sociais divididas - o Facebook e o Twitter são elitistas, enquanto o Orkut é dos pobres -, num futuro breve essa será uma discussão fora de lugar. E, de um jeito ou de outro, a Comunicação está acontecendo, fato que já nos obriga a se deter sobre esses instrumentos e repensar conceitos basilares que, por conta da modernidade, precisam ser lidos e interpretados sob outra perspectiva.

É muito fácil descobrir um sem-número de áreas temáticas em que a hipótese de Agenda setting continue funcionando perfeitamente, destacando entre elas a indústria do entretenimento. É muito frequente que programas populares da TV, como novelas, minisséries, reality shows e partidas de futebol, atinjam o status de trending topics, quando não dominem por completo a lista. São assuntos amplamente debatidos no Facebook, em comunidades do Orkut, nos comentários dos vídeos do YouTube. A conversação cotidiana sobre um capítulo ou um personagem do programa favorito também está presente no mundo virtual ${ }^{17}$. Por outro lado, quando passamos para a conversação política, pairam muitas dúvidas se a teoria do agendamento ainda é tão efetiva quanto era antes de nos transformarmos em uma sociedade em rede.

17 De $1^{\text {o de março a }} 31$ de outubro de 2012, o termo "Avenida Brasil" foi recordista com milhões de tuites e, em seu último capítulo, foram 3.031 tuítes por minuto, informa o blog do Twitter. Disponível em http://blog.pt.twitter. com/2012/12/este-ano-no-twitter.html. Acesso em: 15 abr 2013. 
Até que ponto os eleitores de Serra apostaram em outras redes sociais e abandonaram o Twitter, deixando que os apoiadores de Dilma ocupassem esse espaço, é uma questão que não se consegue responder. Tampouco é possível chegar à conclusão de que Folha e Veja tenham perdido a capacidade de agendar discussões políticas. Mesmo nas situações em que as duas publicações foram alvo dos ataques de parte dos eleitores, o que prova a presença de muitos TTBrs com essa conotação, é indiscutível que os debates muitas vezes giravam em torno do conteúdo midiático. Esse novo tipo de relacionamento entre público e veículos de Comunicação nos obriga a aperfeiçoar as técnicas e metodologias para aperfeiçoar os estudos clássicos de emissão e recepção.

\section{Conclusão}

Pode-se sempre argumentar que as eleições democráticas são um caso à parte no campo das Comunicações, por se tratarem de um momento único e peculiar da vida de uma sociedade. Assim como é possível dizer que num país onde o abismo social se torna ainda mais visível e problemático no mundo tecnológico o olhar estrito sobre as redes sociais obscurece o debate sobre as grandes questões. Não há por que negar tais questionamentos, uma vez que são legítimos e fazem parte da nossa realidade. No entanto, se observarmos com um pouco mais de generosidade os diversos caminhos que nos foram proporcionados com a internet, não é difícil perceber que poucas vezes na História houve tantas chances de debatermos o nosso futuro. A Comunicação e as redes na era digital estão em profunda transformação, desmoronando nossas convicções, pondo em xeque conceitos enraizados e propondo novas indagações.

O Brasil é um país também em profunda transformação social, econômica e política. Estamos conhecendo agora o que é viver numa sociedade de consumo de massa, que nos faz sermos as vedetes do mundo em crise econômica. Um jovem da periferia brasileira usa tanto ou mais internet que um senhor de meia idade que vive num sofisticado condomínio fechado. A modernização capitalista se tornou real e isso é também fruto de uma democra- 
cia que já realizou seis eleições seguidas sem qualquer risco de instabilidade institucional. Essa modernização capitalista tardia nos deixa ainda um pouco atrás do mundo mais rico, que costuma vivenciar antes as benesses do mundo tecnológico. Mas isso não impede que os mesmos processos tecnológicos que fazem parte do resto do planeta, de países desenvolvidos ou não, também nos seja acessível a um clique do mouse. E, talvez por causa desse afã de querer fazer parte da modernidade, tenhamos usuários tão ativos e dispostos a se comunicar nas redes sociais.

A análise proposta por esse trabalho sobre o Twitter nasceu da inquietação natural de quem acompanhou, segundo a segundo, minuto a minuto, hora a hora, o desenrolar da última campanha presidencial. Se é verdade que a expectativa pelo jornal do dia seguinte ou pela revista do fim de semana sobreviveu, também é fato que o brasileiro interessado pela política queria saber a todo momento o que as pessoas estavam falando sobre as eleições. E o Twitter foi uma das ferramentas mais aptas para atender essa vontade. Por meio do site, buscava-se saber da repercussão dos fatos de campanha, daquela manchete ou notícia em particular, e, sobretudo, da opinião que os cidadãos conectados não paravam de emitir. Havia uma disputa no ar muito saudável, ainda que possa ser criticada por espelhar parcela reduzida da sociedade brasileira.

E é sob essa perspectiva que não se pode deixar de ficar surpreso com os resultados encontrados aqui. $\mathrm{O}$ descolamento entre o agendamento da mídia e as opiniões emitidas pelos usuários do Twitter durante uma campanha eleitoral, que mobiliza milhões de pessoas, são indicativos do surgimento de variáveis novas no campo comunicacional. A influência esperada do discurso midiático não se refletiu tal como ocorria na era anterior à da sociedade em rede. Ao mesmo tempo, interações cívicas foram percebidas no sentido de criticar, vigiar e neutralizar o noticiário de jornais, revistas e TVs, comportamento que só vem a público em observatórios da imprensa. Se por um lado ainda é preciso mais estudos para conferir ao site o status de um termômetro da opinião pública, por outro já se percebe que ele amplifica esse conceito, e, em alguns casos, ocupa um papel muito além do mero reprodutor de notícias 
originadas na mídia tradicional. Os cidadãos dessa Twittesfera querem ser, a um só tempo, emissores e receptores, produtores e consumidores de notícias, eleitores, simpatizantes ou militantes, políticos e apolíticos. E, se possível, criar os tópicos populares em torno dos quais só se falará deles nas próximas horas.

\section{Referências}

ASUR, S. et all. Trends in social media: persistence and decay. In: FIFTH INTERNATIONAL AAAI CONFERENCE ON WEBLOGS AND SOCIAL MEDIA. Anais... Association for the Advancement of Articial Intelligence, Barcelona, 2011.

BARDIN, L. Análise de conteúdo. Lisboa: Edições 70, 1977.

CHA, M. et al. Measuring user influence in twitter: the million follower fallacy, Journal, ICWSM, 2010.

DELLER, R. Twittering on: Audience research and participation using Twitter. Journal of Audience \& Reception Studies, Sheffield, v. 8, 2011. Disponível em: http://www.participations.org/Volume\%208/Issue\%201/deller.htm. Acesso em: 15 abr 2013.

HERMIDA, A. Twittering the news: the emergence of ambient journalism. Journalism Practice, Vancouver, n. 3, p.297-308, 2010. Disponível em: http:// ssrn.com/abstract $=1732598$. Acesso em: 15 abr 2013.

JENKINS, H. Convergence culture: where old and new media collide. London: New York University Press, 2006a.

. The message of twitter: 'here is is' and 'here $\boldsymbol{i}$ am', 2009. Disponível em: http://henryjenkins.org/2009/08/the_message_of_twitter.html. Acesso em: 5 dez. 2011.

KEIM, N., CLARK, J. Public media 2.0 field report: building social media infrastructure to engage publics, 2009. Disponível em: http://www.centerforsocialmedia.org/future-public-media/documents/field-reports/public-media-20 -field-report-building-social-media-infra. Acesso em: 5 dez. 2011.

LANG, K., LANG, G.E. The Mass Media and Voting. In: BURDICK-BRODBECK (Eds.). American Voting Behavior. New York: Free Press, 1962. p.678-700. 
LERMAN, K., GHOSH, R. Information contagion: an empirical study of the spread of news on digg and twitter social networks. In: 4TH INTERNATIONAL CONFERENCE ON WEBLOGS AND SOCIAL MEDIA. Anais...George Washington University, Washington, DC. 2010.

MCCOMBS, M. E., SHAW, D. L.The evolution of agenda-setting research: twenty five years in the marketplace of ideas. Journal of Communication, Chicago, v. 43, n. 2, p.68-84, 1993.

MURTHY, D. Twitter: Microphone for the masses? Media Culture Society, London, v.33, p.779-788, 2011. Disponível em: http://mcs.sagepub.com/content/33/5/779. Acesso em: 15 abr. 2013.

ROMERO, D.M., MEEDER, B., KLEINBERG, J. Differences in the mechanics of information diffusion across topics: idioms, political hashtags, and complex contagion on twitter. In: 20TH INTERNATIONAL CONFERENCE ON WORLD WIDE WEB. Anais... New York, 2011.

ROSSINI, P.G.; LEAL, P.R.F. A decisão eleitoral na era das redes sociais: a perspectiva da lógica social do voto. In: XXXIV CONGRESSO BRASILEIRO DE CIÊNCIAS DA COMUNICAÇÃO. Anais.... Intercom, Recife, 2011.

SHAW, E. Agenda-setting and Mass Communication Theory. Gazette - International Journal for Mass Communication Studies, Amsterdan, v. 25, n.2, p. 96-105, 1979. Disponível em: http://gaz.sagepub.com/content/25/2/96.full. pdf + html. Acesso em: 15 abr 2013.

STEFFEN, C. Política a 140: um olhar exploratório no Twitter na campanha presidencial de 2010. In: XXXIV CONGRESSO BRASILEIRO DE CIÊNCIAS DA COMUNICAÇÃO. Anais... Intercom, Recife, 2011.

WOLF, M. Teorias das comunicações de massa. Tradução Karina Jannini. 3. ed. São Paulo: Martins Fontes, 2008. 